University of Warwick institutional repository: http://go.warwick.ac.uk/wrap This paper is made available online in accordance with publisher policies. Please scroll down to view the document itself. Please refer to the repository record for this item and our policy information available from the repository home page for further information.

To see the final version of this paper please visit the publisher's website. Access to the published version may require a subscription.

Author(s): T. D. Veal, P. H. Jefferson, P. D. C. King, S. A. Hatfield, C. F. McConville, J. Zúñiga-Pérez, and V. Muñoz-Sanjosé

Article Title: Surface electronic properties of undoped InAIN alloys

Year of publication: 2008

Link to published version:

http://dx.doi.org/ 10.1063/1.2896605

Publisher statement: None 


\title{
Response to "Comment on 'Bandgap and effective mass determination of epitaxial cadmium oxide"” [Appl. Phys. Lett. 92, 106103 (2008)]
}

\author{
T. D. Veal, ${ }^{1}$ P. H. Jefferson, ${ }^{1}$ P. D. C. King,${ }^{1}$ S. A. Hatfield, ${ }^{1}$ C. F. McConville, ${ }^{1, a}$ \\ J. Zúñiga-Pérez, ${ }^{2, b)}$ and V. Muñoz-Sanjosé ${ }^{2}$ \\ ${ }^{1}$ Department of Physics, University of Warwick, Conventry, CV4 7AL, United Kingdom \\ ${ }^{2}$ Departamento de Fisica Applicada y Electromagnetismo, Universitat de Valènica, C/Dr. Moliner 50, \\ 46100 Burjassot, Spain
}

(Received 20 February 2008; accepted 21 February 2008; published online 13 March 2008)

[DOI: $10.1063 / 1.2896605]$

In our recent letter, ${ }^{1}$ we used a combination of infrared reflectivity, optical absorption, and Hall effect measurements to determine that the room temperature band gap and conduction band minimum effective mass of $\mathrm{CdO}$ are $2.16 \pm 0.02 \mathrm{eV}$ and $0.21 \pm 0.01 m_{0}$, respectively. In their comment, ${ }^{2}$ Coutts and Young correctly point out that, while we cited their review article on transparent conducting oxides (TCOs), we did not compare our result with their value of $0.14 m_{0}$ for the conduction band minimum effective mass of $\mathrm{CdO},{ }^{3}$ obtained from the method-of-four coefficients. However, their comment does not mention that in Table I of their article, when summarizing the properties of three binary TCOs, they give the effective mass of $\mathrm{CdO}$ as between $0.18 m_{0}$ and $0.25 m_{0}{ }^{3}$ a range our value of $0.21 m_{0}$ falls within.

Additionally, Coutts and Young stated that we ${ }^{1}$ did not comment that their "estimate agreed closely with that obtained by Koffyberg, ${ }^{4}$ whereas [our ${ }^{1}$ ] value does not agree." We did not make this comment because it is not correct. Koffyberg did not obtain an electron effective mass in his paper. ${ }^{4}$ As we noted in our letter, ${ }^{1}$ the "calculations on which [Koffyberg's] work is based used a parabolic conduction band and an electron effective mass of $0.14 m_{0}$. No justification for the choice of effective mass value was given." Koffyberg's data modeling used the ratio of the reduced mass and the conduction band effective mass $|\mu| / m_{c}^{*} .4$ Therefore, the conduction band effective mass itself was not deter-

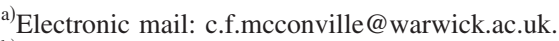

${ }^{b}$ Present address: CNRS-CRHEA, rve Bernard Grégory; 06560 Valbonne, France.
}

mined. Furthermore, Koffyberg himself questioned the value of $|\mu| / m_{c}^{*}$ that he obtained from the data analysis. According to Koffyberg's earlier papers on $\mathrm{CdO},{ }^{5,6}$ it would appear that the conduction band effective mass value of $0.14 m_{0}$, stated in Ref. 4 without any citation of the work from which it was taken, is actually from the work of Finkenrath and von Ortenberg. ${ }^{7}$

It is not completely clear why our conduction band minimum effective mass value of $0.21 m_{0}$ for $\mathrm{CdO}$ differs from the value of $0.14 m_{0}$ determined by Finkenrath and von Ortenberg $^{7}$ and Coutts et al. ${ }^{3}$ However, the fact that our samples are single crystal $\mathrm{CdO}(001)$ films, ${ }^{1,8}$ while those of Coutts et al. are polycrystalline $\mathrm{CdO}$ films, ${ }^{3}$ may have a significant effect on both the electronic properties and how these properties manifest themselves in the different experimental techniques.

Finally, we dispute the claim of Coutts and Young that their measurements are more detailed than ours. ${ }^{2}$ Our respective methods are simply different.

${ }^{1}$ P. H. Jefferson, S. A. Hatfield, T. D. Veal, P. D. C. King, C. F. McConville, J. Zúñiga-Pérez, and V. Muñoz-Sanjosé, Appl. Phys. Lett. 92, 022101 (2008).

${ }^{2}$ T. J. Coutts and D. L. Young, Appl. Phys. Lett. 92, 106103 (2008), preceding article.

${ }^{3}$ T. J. Coutts, D. L. Young, X. Li, W. P. Mulligan, and X. Wu, J. Vac. Sci. Technol. A 18, 2646 (2000).

${ }^{4}$ F. P. Koffyberg, Phys. Rev. B 13, 4470 (1976)

${ }^{5}$ F. P. Koffyberg, Phys. Lett. 30A, 37 (1969).

${ }^{6}$ F. P. Koffyberg, J. Solid State Chem. 2, 176 (1970).

${ }^{7}$ H. Finkenrath and M. von Ortenberg, Z. Angew. Phys. 23, 323 (1967).

${ }^{8}$ J. Zúñiga-Pérez, C. Munuera, C. Ocal, and V. Muñoz-Sanjosé, J. Cryst. Growth 271, 223 (2004). 